\title{
Pensando en clave psicosocial y confesional. Testimonios dentro de los albergues de migrantes
}

Jorge Antonio Morales Cardiel ISSN IMPRESO 1870-7599 | ISSN RED CÓMPUTO 2448-7783 | 179-192

La Ley de Migración en México promulgada en 2011 faculta a la Secretaría de Gobernación, a través del Instituto Nacional de Migración, para que celebre convenios de colaboración con dependencias y entidades de la Administración Pública Federal, entidades federativas, municipios y organizaciones de la sociedad civil y particulares (art. 70 LM) a fin de que ofrezcan servicios de asesoría y representación de los migrantes en situación migratoria irregular o bien a aquellos que hayan iniciado un procedimiento administrativo migratorio. Este último aspecto es de vital importancia porque es el fundamento para la consolidación de albergues y casas del migrante a lo largo del territorio mexicano.

Dicha Ley de Migración suscribe que las organizaciones pueden implementar acciones que coadyuven en la asistencia y protección a migrantes. De igual modo, insta a que se implementen acciones que brinden una atención adecuada a los migrantes en situación de vulnerabilidad (art. 72 y 73 LM), por ejemplo, los inmigrantes indocumentados que se acompañan en la Casa del Migrante Saltillo y la Casa Emaús de Ciudad Acuña, albergues a los cuales se tuvo acceso durante los años 2015 y 2016 respectivamente, para escuchar los testimonios de los inmigrantes establecidos por diferentes periodos y a quienes se les apoyó con la finalidad de continuar con su tránsito migratorio.

Clave psicosocial, cuando el tránsito se convierte en origen y destino. La Casa del Migrante de Saltillo

El nombre legal de La Casa del Migrante de Saltillo es Frontera con Justicia A.C. Saltillo es la capital del estado de Coahuila de Zaragoza, el lugar se encuentra bordeado por la Sierra Madre Oriental, se trata de una las ciudades más industrializada del norte del país, en específico por el ramo automotriz. Está dividida por las vías del tren que se dirigen hacia la ciudad fronteriza de Piedras 
Negras y hacia Monterrey. Cuenta con una población de 823 mil 128 habitantes, según el Censo de Población y Vivienda de 2010.

El porcentaje por nacionalidades de las personas que pernoctaron en el albergue en 2015 se desglosa a continuación: Honduras (81 por ciento), El Salvador (10 por ciento), Guatemala (7 por ciento), Nicaragua (2 por ciento), este último se halla a la baja. Existe una enorme diferencia entre las nacionalidades de las personas que recibe el albergue, de ahí que dentro de la casa se rumora que es una sucursal catracha. ${ }^{1}$ Tal es el caso de Anthony, Rommel y Abrahán, inmigrantes pertenecientes al grupo étnico garífuna, originarios de Santa Rosa en la región de la Ceiba, en el caribe hondureño. Ellos externaron su deseo de arribar lo más pronto posible a Estados Unidos, puesto que debido a sus características étnicas son maltratados en México durante su tránsito migratorio, es como una especie de doble rasero, tanto por ser afroamericanos como inmigrantes indocumentados. No obstante, una vez en Estados Unidos su situación cambia diametralmente, ya que se «mimetizan» con el resto de los afroamericanos. Un elemento a su favor es que la mayoría de los pertenecientes a este grupo hablan inglés.

Desde La Ceiba hasta Saltillo los tres parientes hondureños tardaron en llegar alrededor de un mes, se valieron de diferentes medios de transporte (tren, autobús, a pie y de "aventón») y descansaron en diversos albergues de la ruta. Anthony, el mayor y supuesto tío de Rommel y Abrahán, comentó que es importante pensar en los migrantes que vienen detrás, por eso no pueden prolongar su estancia en las casas de migrantes. Se observa un rápido proceso de adaptación cultural dentro de la sociedad norteamericana, además poseen más y mejores contactos para cruzar la frontera, aunado a que las redes están más consolidadas, incluso el propio Anthony las conoce y domina.

En sus inicios, en los albores de 2002, el albergue daba asistencia humanitaria en cuartos rentados en un lugar distinto al actual, poco después su fundador, el padre Pedro Pantoja, ${ }^{2}$ consiguió una bodega donada por Cáritas. Al principio, la

\footnotetext{
${ }^{1}$ Gentilicio coloquial sinónimo de hondureño.

${ }^{2}$ El padre Pedro Pantoja tiene una larga trayectoria en el activismo religioso, ha sido instruido en la teología de la liberación a través de la defensa de los derechos humanos hacia los inmigrantes en el norte de México. La teología de la liberación ha tomado cuerpo en Latinoamérica al querer hacer de la Iglesia, una Iglesia del pueblo. A su vez compara y sustenta su trabajo de formación hacia la inmigración indocumentada con la carta de Jeremías, al introducir el tema de la subjetividad social, pues al igual que el profeta hebreo, aconseja a los desterrados que se conviertan en constructores y protagonistas en el nuevo país (Pantoja, 2013). Otra fuente de inspiración se encuentra en la encíclica
} 
colonia donde se ubica ${ }^{3}$ era renuente con la convivencia y atención brindada al inmigrante. En ese entonces el mayor apoyo lo recibía del Banco de Alimentos, éste realizaba descuentos significativos que hasta la fecha siguen vigentes, así como las donaciones de pobladores de ejidos cercanos, «quienes por el carisma del padre Pedro Pantoja decidieron apoyar» (Tavera, 2014).

Previo al comienzo de la guerra contra el narcotráfico en 2006, a partir de la cual se desataría una ola de violencia inusitada en contra de los inmigrantes indocumentados, la Casa del Migrante de Saltillo recibía en promedio a trescientas personas inmigrantes de Centroamérica a la semana. La cifra ha variado de modo contundente hasta regularizarse en el presente a doscientas personas al mes. Las autoridades del Gobierno Federal a mediados de 2014 implementaron el Programa Frontera Sur, hecho que mermó considerablemente el tránsito de inmigrantes procedentes del triángulo de Centroamérica o en su defecto ha reorientado el flujo de personas hacia otras rutas.

A fin de comprender la aplicación y los resultados del acompañamiento, es necesario escuchar los testimonios que a diario se viven dentro de la Casa del Migrante. Con base en las 19 entrevistas realizadas, alrededor del 90 por ciento de los inmigrantes que llegan al albergue traen consigo una fuerte carga emocional a causa de distintos hechos violentos ocurridos durante su tránsito por México; desde asaltos con violencia, intentos de lapidamiento, humillaciones, extorsiones, secuestros, ultraje sexual hasta mutilaciones, tortura y trabajos forzados.

Mediante los testimonios recabados de migrantes «sin papeles», «indocumentados» o «irregulares» como erróneamente se les conocen, no se constató que tuvieran una estancia prolongada en el albergue; hombres, mujeres y menores de edad pertenecen a tres principales nacionalidades: hondureña, salvadoreña y guatemalteca. Asimismo, se observó que antes de salir reaparecen los miedos y el estrés por las vicisitudes acaecidas durante el tránsito migratorio.

Otto Alexander, inmigrante de origen salvadoreño de 57 años, es prueba fehaciente de lo anterior. Posee fuertes problemas de la vista al punto de quedar completamente ciego del ojo derecho. No tiene claro su destino, ni siquiera certeza del resto del viaje, sabe que Texas está cerca de Saltillo, desafortunadamente

de los Hebreos 13,2: «No cierres la puerta al extranjero, no sea que no dejes pasar al ángel». También fundó en 1998 la Casa Emaús en la fronteriza Ciudad Acuña, Coahuila, albergue que acompaña a los deportados mexicanos.

${ }^{3}$ La colonia Landin, ubicada al poniente de la ciudad, pertenece una de las zonas más populares e inseguras de Saltillo; en México a estos sitios se les suele denominar «barrio» o «arrabal». 
no cuenta con un lugar preciso de llegada, pues carece de los contactos que se requieren para cruzar del otro lado, ni siquiera en su propio país tiene familia. Por tanto, la ayuda de los albergues es determinante en su caso. Otto, al momento de la entrevista cumplió cuatro meses de estadía. Aunque en tres ocasiones se quedó en el albergue, en una le tocó vivir el drama de la deportación de México a su país. De acuerdo con su testimonio, los albergues no han tenido mucho éxito, incluso sufrió un accidente que lo afectó profundamente en Tapachula, en la frontera sur, del que no quiso ahondar más, pero del que con seguridad deriva el origen de la falta de visibilidad.

Afirma que afuera (del albergue) existen fuertes barreras para la migración, sobre todo la inseguridad que en su opinión es el más afanoso. Otto es una persona muy cercana a los coordinadores y voluntarios de la casa, todos se han acostumbrado a su andar tranquilo al interior de ella, es uno de los más participativos en las oraciones, puesto que la ayuda celestial es para él la única forma de romper dichas barreras. Refiere que las personas del albergue poseen un corazón noble, ahí él ha encontrado el cobijo espiritual que necesitaba, por esa razón no quiere pensar en el momento inminente de su salida. Vive con el temor de que le vuelva a ocurrir lo que le pasó en las vías del tren cuando se accidentó, esas vías están justo a unos metros del albergue; diario escucha el paso del tren, hecho que le provoca mucha aprehensión.

Son diversas las causas dentro del acompañamiento en migraciones indocumentadas que hacen que el tránsito se convierta en origen y destino en un momento específico. Hemos señalado varios lazos de «pertenencia» al lugar, las redes sociales que se desprenden de la práctica religiosa como un elemento valioso a considerar en la integración en la sociedad de acogida. De igual modo, destaca la información acerca de los derechos más elementales que se brinda durante la estancia en algunos albergues; por ejemplo, el asesoramiento legal dentro de la Casa del Migrante de Saltillo, en relación con el asilo y el refugio político.

Sobresale el caso de Carlos, un joven de 24 años de origen hondureño, de San Pedro Sula. Su historia es una de las más conmovedoras del albergue. Más que la entrevista, fue la cercanía con él y los relatos de sus compañeros lo que influyó para conocer lo que había detrás de su proceso legal de asilo político. Carlos fue miembro de las maras en su ciudad natal, decisión que en múltiples ocasiones es irreversible, pues es sumamente difícil desertar de ellas. Carlos pagó muy caro su salida de las maras, porque su propia pandilla asesinó a su madre, él supo de esta lamentable noticia estando en México. 
No es sencillo imaginar la impotencia y el duelo que sintió al enterarse de lo acaecido, no obstante, gracias a su valor, su esfuerzo y dedicación salió adelante, incluso vislumbró un futuro distinto en México, ya no en los Estados Unidos como algún día lo pensó cuando salió de su país. Ahora Carlos cuenta con la visa humanitaria derivada del acompañamiento legal dentro de la Casa del Migrante de Saltillo, un proceso nada fácil pero que al final se logró por las características del caso. Posteriormente trabajó en la jardinería, primero en Saltillo y después en Monterrey, luego se instaló de manera permanente en Tijuana. Su acto resulta heroico, puesto que puso en peligro no sólo su vida sino el derecho que había ganado para estar de forma legal en el país. Decidió regresar por el resto de su familia, la cual padecía las mismas represalias; una hermana y dos sobrinos burlaron la seguridad fronteriza y el cerco de las propias maras, ingresaron al país encima de la Bestia, ahora su familia está con él, construyendo un nuevo destino en Tijuana.

Lesly, de 48 años, es otro caso más de estancia prolongada dentro del albergue por motivos legales. Proviene de la capital hondureña, Tegucigalpa, viaja sola y al igual que Otto y Carlos ha tenido que extender su estancia en el albergue por varios meses. Tiene a su familia dividida: sus hijas están en Honduras y su esposo, de origen salvadoreño, radica en Maryland, Estados Unidos. Sin duda se trata de una auténtica familia transnacional con una estrategia migratoria de reunificación que consta de varias etapas.

Es la segunda vez que se instala en la Casa del Migrante de Saltillo, en 2007 pudo ingresar a los Estados Unidos y reunirse con su esposo; sin embargo fue deportada en una redada en 2010 por Mexicali, ciudad donde trabajó durante dos años. Luego de su deportación estuvo dos meses en Honduras hasta planeó su nuevo proyecto migratorio. La experiencia de Lesly es fundamental para recorrer la ruta de tránsito, sea en albergues o trabajando por su cuenta fuera de ellos. Ha descubierto que mediante el «papeleo» migratorio, que es posible tramitar en albergues, hay opciones más viables y seguras para trabajar en México, y esperar a que se den las condiciones de volver a cruzar.

Se podría decir que es una estrategia "mixta», que practican varios inmigrantes irregulares en su tránsito, sobre todo cuando éste se extiende e involucra trámites legales desde México como la visa humanitaria y otros trámites no reglamentados como la contratación de un buen pollero para atravesar la frontera. En el caso de Lesly correrá por parte de su esposo desde el norte cuando sea el momento adecuado; mientras tanto, el objetivo de sus tres hijas es instalarse y reunirse con su madre en Saltillo en un corto plazo. 
Sorprende que esta suerte de «estrategia mixta» sea usada por otros singulares personajes de la migración indocumentada, igual de transnacionales. A fin de cuentas un trámite de visado inhibe la supuesta irregularidad en el tránsito migratorio y permite trabajar de forma más segura y ordenada al trabajador migrante, cualquiera que sea la actividad que desempeñe, por ejemplo, ayudar a otros a cruzar la frontera sur de México y trasladar a esas mismas personas a lo largo del país hasta la otra frontera norte.

Así sucede con Paco, otro hondureño de 46 años, quien dice ser un exreservista del ejército nacional de Honduras en los 1990, según él esto le ha dado uno de las mejores habilidades que pueda tener cualquier persona; las relaciones humanas y los primeros auxilios, le favorece en su peligrosa labor de ayudar a otros connacionales a trasladarse por la ruta de la migración irregular desde su país, actividad que ejecuta desde hace diez años. Ya estuvo en la ciudad de Washington y retornó voluntariamente a su país en 2011.

Conoce muy bien la ruta migratoria en la que se puede trasladar en tren y autobús, ello lo convierte en un excelente guía no autorizado sobre el territorio mexicano por sus conocimientos geográficos. En los últimos cuatro años antes de 2015 el destino de Paco, cada vez que se aventura a migrar es México, no los Estados Unidos como el grueso de los inmigrantes de su país. Ahora espera en el albergue la posibilidad de que se le renueve la visa humanitaria para seguir trabajando de forma más tranquila en lo que se ha estado especializando: el coyotaje. En términos generales, la decisión de prolongar su estancia ocurre por múltiples factores: falta de dinero para continuar el viaje, a veces se les termina, otras son agredidos o asaltados, incluso por las autoridades gubernamentales; esperan el depósito de más recursos económicos por parte de algún familiar; problemas de salud; y de forma esporádica, por desinformación.

En la mayoría de los casos se documentó que dicha situación produce efectos contrarios a los planeados inicialmente; el principal es que durante el viaje vuelvan a surgir estos mismos aspectos desalentadores. Permanecer más tiempo en los albergues provoca que los inmigrantes no sepan qué hacer con su cotidianidad, de ahí su desesperación y desmotivación al darse cuenta del transcurso inevitable del tiempo, hecho que ocasiona fuerte estrés.

Laura, otra mujer inmigrante de origen hondureño, de cincuenta años, se dirige a Dallas, Texas. A lo largo de tres meses ha permanecido en el albergue; ingresó al país por Tapachula, Chiapas, y lo recorrió en un promedio de un mes, al igual que el resto. El monitoreo hacia ella por parte del personal de la casa se 
debe a una condición especial: sufrió una mutilación de su pie derecho al quedar atrapada entre los rieles del tren cuando intentaba sacar una blusa de su mochila antes de subirse. Cuando sucedió esto viajaba en la Bestia a través del desierto de San Luis Potosí.

Gracias a una compañera de viaje Laura pudo recibir atención médica, pero tuvo que esperar durante horas en medio del desierto hasta que perdió la esperanza del regreso de su amiga. Pese a su condición volvió a trepar a los hombros de la Bestia para continuar la travesía, justo en ese momento recuerda que con un garrotero del ferrocarril pudo bajar porque la ambulancia ya estaba cerca. Después fue trasladada a un hospital donde le amputaron la pierna desde la rodilla. Laura considera que no debió haber sido así, puesto que sólo se había dañado el pie. Probablemente se trató de una negligencia médica, en lo que se ha vuelto un procedimiento de rutina de ciertos hospitales ante la incidencia de percances de tal tipo con inmigrantes en las vías.

Tres días después personal del consulado de Honduras en Saltillo la trasladaría al albergue todavía delicada, según comenta; de igual modo, el consulado de su país la apoyaría al principio con los medicamentos. Ahora, por medio de Caritas y el albergue de Saltillo, se gestiona una prótesis que sustituya sus muletas y silla de ruedas. Sorprendentemente su deseo de cruzar a Estados Unidos sigue vigente, pues anhela reencontrarse con su esposo y que a la vez sus cuatro hijas se trasladen desde San Pedro Sula por el mismo camino a fin de lograr estar juntos en el norte. Sus parientes han seguido desde la distancia el drama que ha vivido.

Por otra parte, cuando el tránsito se convierte en origen, en el caso de las personas inmigrantes que deciden regresar a su país, existe la posibilidad del retorno asistido; se presenta en el momento en que se entregan a las autoridades de migración para que los devuelvan a sus países (las autoridades mexicanas lo hacen a través de autobuses, no así en Estados Unidos que lo ejecuta en aviones, "los vuelos de la vergüenza», como se denominan en España). Algunos deciden montar de nuevo en los hombros de la Bestia, pero en dirección opuesta, de norte a sur, - a fin de cuentas es más seguro—; otros deambulan una temporada más por México antes de llegar a sus destinos. Sin embargo, corren el riesgo de caer en la trashumancia, como José Temal, indígena achí de origen guatemalteco quien habla un español fluido y dice dirigirse «hacia donde Dios lo ponga». Comenta que el resto del grupo que viajaba con él, fue bajado y golpeado brutalmente por la policía. Respecto a él, asegura que gracias a la biblia con la que viajaba en su mochila no sufrió mayores daños en este hecho violento. 
Aunque llegó hasta Piedras Negras en la frontera norte en Coahuila no quiso cruzar, decidió regresar al sur a Saltillo. No tiene miedo de estar en la ruta migratoria, comenta que disfruta de los paisajes cuando viaja encima del tren. En realidad José no tiene familia ni dinero para atravesar la frontera, en los cuatro meses de vagar por el país ha conseguido trabajar en la albañilería, vendiendo lo que puede y pidiendo la clásica charola en los cruceros de las ciudades en las que ha estado: "Prefiero estar así de errante que estar en los albergues y planear un mejor destino».

En cualquier situación, o forma de realizar el tránsito sea de origen o destino, se documentó que dentro de la casa de migrantes no es una situación sencilla, ya que las personas regresan con sentimientos encontrados. Por un lado, aparece la alegría de retornar a casa y reunirse con su familia después de meses de ausencia e incertidumbre; experimentar de nuevo la libertad, lejos de arrestos, extorsiones y trámites legales, además del trato policial durante la deportación. Por otro lado, persiste un fuerte desánimo y desmotivación al no haber alcanzado las metas propuestas, el anhelado sueño americano que terminó por convertirse en una pesadilla mexicana.

\section{Clave confesional en ciernes al repatriado mexicano. El albergue Emaús en Ciudad Acuña}

En el mismo estado de Coahuila, pero más al norte, limítrofe con Estados Unidos, se encuentra Ciudad Acuña. En este sitio existe un proceso diferente de acompañamiento hacia las migraciones y otro tipo de actores involucrados. El acompañamiento se brinda hacia los migrantes mexicanos que han sido repatriados, capturados en su intento de cruzar la frontera, detenidos por infringir la ley o bien a los que han terminado de pugnar su periodo en prisión en determinada cárcel de Estados Unidos (algunos de éstos debido a su reincidencia en el intento de cruzar). La asistencia humanitaria y acompañamiento se da a través de la palabra de Dios, por parte de la Iglesia Católica en la Casa Emaús.

Ciudad Acuña cuenta con una población de 134 mil 233 habitantes, es limítrofe con la ciudad Del Río, en el estado de Texas, ambas separadas por el río Bravo. La casa Emaús se localiza a tan sólo cien metros de este río y a la misma distancia del puente internacional Puerta de México, por donde devuelven a los 
migrantes repatriados. Ciudad Acuña es la sede de dicho albergue al final del camino de la ruta de la hospitalidad de las migraciones de tránsito centroamericanas, o mejor dicho, el principio de la otra ruta de la hospitalidad para los repatriados mexicanos.

Para aquellos que sobrevivieron en su intento de cruzar el río o el desierto al momento de ingresar ilegalmente a Estados Unidos representó, como en el pasaje bíblico de Emaús, una auténtica victoria sobre la muerte. Dos entrevistados en la casa relataron esta aventura, Rafael y Roberto Carlos: el primero lo cruzó durante 15 días con una mochila que pesaba alrededor de 40 kilos, pues cargaba la comida del grupo; caminó hasta quedar completamente agotado y deshidratado, al punto de decidir entregarse a la Patrulla Fronteriza con el propósito de recibir asistencia. El segundo pasó dos noches a la intemperie en el mismo desierto hasta casi morir de hipotermia, expuesto a verdaderos riesgos naturales. Ambos se habían separado del grupo que los acompañaba después de sufrir varias redadas.

Emaús significa el camino, así como analógicamente este albergue intenta serlo con los miles de repatriados que atraviesan Ciudad Acuña año tras año; su objetivo es brindarles un lugar de descanso y refugio en medio de su trasiego migratorio, que no ha terminado a pesar de haber entrado a su país de origen. Para muchos el tránsito migratorio, por muy irónico que sea, apenas comienza, debido a la estrategia de seguridad de Estados Unidos de deportarlos de oeste a este de la frontera física mexicana, de la zona desértica a la región del río Bravo y viceversa que divide a los dos países.

En 2015 pasaron por Ciudad Acuña más de 42 mil repatriados, lo que convirtió a la ciudad en el segundo punto fronterizo de mayor afluencia, detrás de Matamoros, Tamaulipas, y a la delantera de otros puntos de mayor importancia como Tijuana o Ciudad Juárez. El Instituto Nacional de Migración (INM) los recibe sólo con una hoja de repatriación y les proporciona cierta orientación hacia la central de autobuses, el comedor comunitario o el albergue Emaús, no sin antes atravesar un ejército de especuladores financieros ambulantes que intentan cambiarles los dólares que llevan consigo o los que están por enviarles.

Concerniente a 2016, de enero a marzo, transitaron 413 personas (mil 200 personas al año); todos son varones de nacionalidad mexicana, deportados de Estados Unidos por no tener documentos que avalen su residencia, su promedio de edad era de 35 años. La mayor parte provenía del interior de México, pero resaltan los estados de Guerrero, Sonora y Sinaloa, los dos últimos pertenecientes 
a la región transfronteriza del noroeste del país. En la actualidad Emaús brinda hospedaje por tres días a las personas deportadas siempre y cuando cuenten con su hoja de repatriación y tenga vigencia del mismo día. Además de la cena y el hospedaje, en ocasiones se les puede dar un cambio de ropa, ya que algunos llegan vestidos todavía con el uniforme de la prisión, un conjunto de pants color blanco o naranja.

La delegación local del INM estima que 85 por ciento de las personas que ingresan por Ciudad Acuña no se queda en la ciudad, la mayoría toma el primer autobús que puede, el resto se queda algunos días, otros buscan refugio en la Casa Emaús; los menos, desafortunadamente, permanece en las calles sin ningún tipo de atención básica, propensos a la indigencia (Zócalo, 6 de octubre de 2014). Existen casos en los que los repatriados deciden probar suerte en Ciudad Acuña, tal como sucedió con Óscar Rafael, uno de los primeros entrevistados quien fortalecido en la fe cristiana que escuchaba a diario en el albergue se despidió con grandes esperanzas de trascender en esa ciudad.

En entrevista con el padre Hermenegildo, director de la parroquia Santa María Guadalupe, se comentaron puntos clave para entender los pormenores del acompañamiento en Ciudad Acuña. En principio, se trata de una ciudad de tránsito de migrantes mexicanos deportados; es una ciudad fronteriza mexicana «flotante», debido al poco arraigo de las personas que habitan en este lugar al ser oriundos de otros sitios; después por el corto tiempo de estadía dentro del albergue de los repatriados, aunado a su limitada fe en los evangelios; finalmente, a consecuencia de la red de tráfico ilegal de migrantes inmersa en esta urbe.

La violencia y los problemas sociales terminaron por convertir a Ciudad Acuña en un lugar de paso, en una ciudad «flotante», como indica el padre Hermenegildo, además en los últimos años ha sido el lugar preferido para las deportaciones de migrantes por parte de las autoridades norteamericanas. Incluso es una estrategia de seguridad de la Patrulla Fronteriza el regresar por Ciudad Acuña a los que fueron capturados en su intento de cruzar de forma irregular por el otro lado de la frontera, entre los estados de Sonora y Arizona. Es bien sabido que el desierto es el lugar utilizado por el narcotráfico para cruzar droga mediante migrantes indocumentados. Hay claros indicios de que algunos repatriados, incluyendo los albergados temporalmente en Emaús, han sido utilizados para traficar droga por esa ruta y luego repatriados por Ciudad Acuña, lo que los convierte en «burreros», como se les conoce por aquí. 
Un escenario que nos conduce a la decisión que tomaría el joven Manuel, de 26 años, oriundo de Los Mochis, Sinaloa, que no dista mucho de la historia de Rafael y Roberto Carlos con relación a su experiencia fronteriza. Manuel, a pesar de tener estudios de preparatoria y técnicos en enfermería, se dispuso a emprender este peligroso viaje por una única ocasión, su intención era meramente por motivos económicos. El origen de su proyecto migratorio comenzó en la ciudad sonorense de Caborca, donde conectó con el resto de los «burreros» que se internarían en el desierto. Debido a la complexión robusta se le encomendó cargar gran parte del agua y la comida para un grupo de nueve personas, cuyo tránsito comprendería 15 días con sus respectivas noches; calcula que la mochila pesaba alrededor de 50 kilos.

Luego de quedar extraviado en medio del desierto, aturdido, exhausto, lleno de callos en los pies, sin alimento alguno o agua, explica que tomó la decisión de entregarse a "la migra» para ser deportado, pues el resto de su grupo se había internado ya en territorio estadounidense y se había olvidado de él. Dos días después fue deportado por Ciudad Acuña, lugar que desconocía. No obstante, al realizar un par de llamadas ahora tiene algunos dólares que le ayudarán a regresar a su ciudad a intentar replantearse qué hacer con su vida, porque reafirma su deseo de no repetir esa experiencia migratoria irregular.

Desafortunadamente, en la actualidad semejante situación se ha convertido en una práctica común y en una fuente de ingresos para jóvenes del noroeste mexicano. Se desconoce si lo realizan de forma voluntaria o involuntaria. Algunos de ellos pertenecen a los grupos indígenas de la zona (yaquis, navajos y mayos) y otros son de clase media como Manuel, que ante la falta de fuentes de empleo que les permitan mejorar la condición de vida en sus lugares de origen deciden emprender ese negocio temporal ilícito.

Tal mecanismo de la Patrulla Fronteriza ("la migra») es considerado en Ciudad Acuña una estrategia cruel e inhumana de parte del gobierno de Estados Unidos; aparte de que ha modificado la organización comunitaria local al reconfigurar el mismo tejido social y las dinámicas económicas de la ciudad, condena a la trashumancia a muchos de los repatriados que deben recorrer miles de kilómetros para regresar a sus lugares de origen o bien intentar cruzar de nueva cuenta sin dinero ni documentos, hecho que los convierte en indocumentados y los expone al tráfico ilícito de migrantes del crimen organizado. Lo anterior desestabiliza incluso las reglas internas de la Casa Emaús, porque regularmente los tres días permitidos son insuficientes para juntar el dinero y poder regresar 
a sus casas, si es que no son «burreros», una estancia prolongada dentro de la casa permite que los enganchadores recluten personas dentro y fuera. Por desgracia, esto sucede cuando la ayuda del gobierno mediante el programa Repatriados Trabajando se suspende.

En sí, alrededor de 70 por ciento de los que se refugian en dicho albergue proviene de Sonora y Sinaloa; sin embargo, los registros con los que se cuenta son también «flotantes», con relación al lugar de origen. Tampoco existe un registro confiable del número de personas que ha llegado desde su fundación, debido a que las diferentes administraciones han manejado distintos formatos o se han extraviado datos de forma misteriosa.

Semejante desorganización interna ha provocado que la ayuda al deportado desde la parroquia sea igual de intermitente, antes hubo periodos de bonanza pero en la actualidad se vive una etapa de atraso y desorganización. El padre Hermenegildo lo aprecia de esa manera, para él forma parte de la «esencia» de su administración, discierne que es el modo en cómo la comunidad religiosa puede ayudar a los repatriados y cómo Jesús ha querido que sea, aún con amplio conocimiento del enfoque psicosocial de la Casa del Migrante de Saltillo, que con anterioridad dirigía el padre Pantoja y quien a su vez fundó la Casa Emaús en 1998.

La austeridad dentro del albergue sólo alcanza para proporcionar un café por la mañana y una cena por la noche. Durante el día, el desayuno y la comida son otorgados por un comedor comunitario que apoya a los adultos mayores; el ayuntamiento de Ciudad Acuña lo abrió reciententemente ante la deportación masiva de migrantes. Al interior el empoderamiento hacia el migrante se realiza a través de la palabra de Dios; no obstante, algunos migrantes repatriados sienten profundamente las enseñanzas del Evangelio, pero otros no. En opinión de don Miguel, uno de los encargados del albergue, la palabra que se transmite no siempre es sensible al género, lugar de origen o preferencia sexual.

La insensibilidad del albergue se refleja en cierta intransigencia hacia algunos deportados que llegan y que requieren mayor atención, más allá del mero asistencialismo. Por ejemplo, la situación en la que se encuentra Óscar Rafael quien fue deportado por Ciudad Acuña luego de purgar una condena de 15 años en varias cárceles del estado de California. Nació en Ensenada, Baja California, desde donde muy joven migraría junto con su familia en 1995 a Los Ángeles. Allí asegura que vivió un proceso de adaptación complejo, al punto de considerarse un ser antisocial. Las mayores dificultades en su juventud se desarrollaron dentro de su 
propia familia a grado tal que su rebeldía lo condujo a formar parte de las pandillas. Desde esos grupos mexicanos de contracultura se involucró en el tráfico de drogas y armas que a la postre lo llevarían a prisión.

Contrario a lo que se podría creer, Óscar Rafael afirma que dentro de las cárceles vivió el único proceso de formación personal, al tomar cursos de inglés, superación personal y sexualidad. Aunque lo más importante fue haberse encontrado consigo mismo mediante un proceso de rehabilitación personal y sanación religiosa. Pese a lo anterior, su reincorporación a la sociedad mexicana desde Ciudad Acuña es complicada, no sólo por los tatuajes que cubren su rostro y cuerpo (representan a las pandillas a las que perteneció), sino por los problemas de esquizofrenia que padece a causa de los castigos que le infligían en la prisión, durante nueve meses fue recluido en un cuarto, ya que los problemas de las pandillas lo persiguieron hasta la prisión. A sus 36 años desea mejorar y ganarse la vida de nuevo en México, no niega que siente cierto temor de enfrentar la realidad. El primer obstáculo es que se encuentra invisibilizado ante el resto de las autoridades, del propio albergue y de la sociedad de acogida.

A diferencia de la Casa del Migrante de Saltillo, en la Casa Emaús no existe el «blindaje social» de la comunidad local con el enfoque de los derechos humanos, tampoco el proceso de acompañamiento psicosocial o legal dentro de la casa, indispensable en casos como los relatados. En contraposición, existe una «permeabilidad social» debido a la ausencia de control de quienes entran o salen del lugar y el enfoque meramente asistencialista hacia el repatriado. No obstante la cotidianidad de las repatriaciones en el paisaje social de Ciudad Acuña, para la mayoría de la comunidad local los migrantes siguen igualmente invisibilizados.

\section{Referencias}

Espinoza, Leticia (6 de octubre de 2014), "Ciudad Acuña: válvula de escape para migrantes», Zócalo, p. 17.

Ley de Migración (2011), Diario Oficial de la Federación, Ciudad de México, Cámara de

Diputados del H. Congreso de la Unión, en http://sre.gob.mx/images/stories/ marconormativodoc/leyes/dof250511.pdf

Morales Cardiel, Jorge Antonio (mayo-agosto de 2017), «Migraciones indocumentadas. Proceso de acompañamiento en países de tránsito», Observatorio del Desarrollo. Investigación, Reflexión y Análisis, 6(17), pp. 87-92. 
Pantoja, Pedro (2013), «Belén, posada del migrante. Experiencia eclesiológica y alternativa social en el dolor y la violencia social de la migración forzada centroamericana», Migración y Desarrollo (21), pp. 177-186.

Tavera, Pilar, Alexis Guillen y Mauricio Pérez (2014), Solidaridad en el camino. Atlas de organizaciones de apoyo a personas migrantes centroamericanas, México, Propuesta Cívica. 